\title{
EXPERIENCE OF
}

\section{THE USE OF BECLOMETHASONE DIPROPIONATE AEROSOL IN GENERAL PRACTICE}

\section{GREGG}

Department of Clinical Epidemiology in General Practice, Cardiothoracic Institute (Brompton Hospital), 11 Birkentread Avenue, Kingston upon Thames, Surrey, UK

1 The findings of an open trial of beclomethasone dipropionate aerosol (BDA), carried out in 1972 in the author's general practice, are discussed in the light of subsequent, more extensive experience of its use of BDA.

2 An important reason why BDA may be unsuccessful in controlling asthma, and may give rise to various problems, is that patients are often given an inadequate explanation of the purpose and proper use of this treatment.

\section{Introduction}

This paper is based on personal experience of the use of beclomethasone dipropionate aerosol (BDA) in general practice over a period of five years. In January 1972 , some 10 months before BDA became prescribable, I began an open study of this new form of treatment in general practice. At that time, no detailed report of the use of BDA had been published, and there were several important questions to which answers were required before BDA came into general use.

The principal aim of the trial was to obtain information about the proper use of BDA in the management of asthma, particularly in the context of general practice. None of the main conclusions reached on the basis of the findings, which have not been published previously, has been altered by subsequent experience of the use of BDA in general practice and in the Out-Patient Department of Brompton Hospital.

\section{Objectives of the study}

Answers were sought to the following questions: (1) How effective is BDA in replacing long-term systemic corticosteroid therapy? (2) How important a factor is pre-existing adrenal suppression, and should assessment of adrenal function be mandatory? (3) How effective is BDA in controlling asthma in patients who have not previously received systemic corticosteroid therapy? (4) What is the nature and incidence of side-effects and other problems, either caused by BDA itself or arising from its substitution for systemic corticosteroids? (5) What difficulties may arise in educating patients about the proper use of BDA?

\section{Patients studied}

All but two of the 39 adults admitted to the study were patients in general practice (Table 1). The first patients who were studied were taking long-term corticosteroid

Table 1 Patients studied

In general practice

In Brompton Hospital Out-Patient Department

Total

'Corticosteroid-dependent'

Corticotrophin

Prednisone not more than $5 \mathrm{mg}$ daily

Prednisone not more than $10 \mathrm{mg}$ daily

Prednisone more than $10 \mathrm{mg}$ daily

Previously received corticosteroids (none within last 3 months)

Never previously received corticosteroids 
therapy. All these 25 'corticosteroid-dependent' patients had already been studied intensively in connection with research into various aspects of asthma and its treatment. They had been followed up, some for as long as eight years, with regular measurements of peak expiratory flow (PEF) carried out before and after the inhalation of isoprenaline aerosol. Of the remaining 14 patients, six had previously received short courses of corticosteroid therapy, whereas eight had never received corticosteroids.

The trial had to be terminated after just over a year, when I moved to another practice. The longest duration of follow-up was 13 months. No patient was followed up for less than 2 months, and more than three-quarters were followed up for at least 6 months.

\section{Substitution of BDA for long-term systemic corticosteroid therapy}

This was regarded as the most important objective of the study, since it was clear that the principal value of BDA lay in the possibility of using it to replace systemic corticosteroid therapy without incurring any of the latter's risks and side-effects.

The substitution of BDA for prednisone was carried out in a manner similar to that used previously to evaluate the corticosteroid-sparing effect of sodium cromoglycate (Gregg, 1970). In all the 25 patients currently taking systemic corticosteroids, at least one unsuccessful attempt had been made to withdraw it. Furthermore, in the course of their follow-up, a continual effort had been made to reduce the maintenance dose of prednisone or corticotrophin to that which just sufficed to prevent a relapse of asthma.

Patients were at first re-assessed weekly. Those in whom systemic corticosteroids were withdrawn without relapse were seen at fortnightly and eventually at monthly intervals. On each occasion PEF was measured before and after the inhalation of isoprenaline.

Before treatment with BDA was started, adrenal function was assessed by a short tetracosactrin challenge test (Greig et al., 1966). The following levels of plasma cortisol were regarded as normal: prechallenge: at least $200 \mathrm{nmol} / \mathrm{l} ; 30 \mathrm{~min}$ postchallenge: at least $500 \mathrm{nmol} / \mathrm{l}$; increment: at least $200 \mathrm{nmol} / \mathrm{l}$.

Adrenal function was considered to be normal if all three criteria were fulfilled, to be borderline if only two criteria were fulfilled, and to be suppressed if only one or none was fulfilled. A second assessment of adrenal function was carried out in all patients not less than I month after systemic corticosteroids had been withdrawn. In those patients in whom the second test indicated that adrenal suppression was still present, further tests were carried out until adrenal function had returned to normal.

All patients initially received BDA $400 \mu$ g daily. In several patients in whom this dose seemed to be insufficient, increases were made to $800 \mu \mathrm{g}$ daily, and in one patient up to $1000 \mu \mathrm{g}$ daily.

The period over which BDA was substituted for prednisone varied from 3-10 weeks, and its length was generally determined by the degree of adrenal suppression shown by the first tetracosactrin challenge test.

Complete replacement of systemic corticosteroid therapy by BDA was achieved in $19(76 \%)$ of those patients whose maintenance dose of prednisone had not exceeded $10 \mathrm{mg}$ daily (Table 2). In several of these patients, measurements of PEF during the period of substitution were higher than those achieved when they had been taking prednisone alone, and this increase in PEF was maintained in a few patients after prednisone had been withdrawn. Several patients in whom prednisone had been replaced by BDA

Table 2 'Corticosteroid-dependent' patients

\begin{tabular}{|c|c|c|c|c|c|c|c|}
\hline \multirow[t]{2}{*}{$\begin{array}{l}\text { Number of } \\
\text { patients }\end{array}$} & \multicolumn{2}{|c|}{ Previous corticosteroid therapy } & \multicolumn{3}{|c|}{ Adrenal function * } & \multicolumn{2}{|c|}{$\begin{array}{l}\text { Complete } \\
\text { substitution } \\
\text { by } B D A\end{array}$} \\
\hline & $\begin{array}{c}\text { Maintenance dose } \\
\text { (mg daily) }\end{array}$ & $\begin{array}{c}\text { (range }+ \text { mean) } \\
(y r)\end{array}$ & $N$ & $B L$ & $S$ & Achi & ailed \\
\hline $\begin{array}{r}1 \\
7 \\
14 \\
3\end{array}$ & $\begin{array}{c}\text { Corticotrophin } 10 \mathrm{U} \\
\text { Not }>5 \mathrm{mg} \\
>5, \text { not }>10 \mathrm{mg} \\
>10 \mathrm{mg}\end{array}$ & $\begin{array}{l}3 \\
1-9(5) \\
1-11(5) \\
4-10(6)\end{array}$ & $\begin{array}{l}1 \\
4 \\
3 \\
-\end{array}$ & $\begin{array}{l}- \\
1 \\
1 \\
-\end{array}$ & $\begin{array}{r}\overline{2} \\
10 \\
3\end{array}$ & $\begin{array}{r}1 \\
7 \\
11 \\
-\end{array}$ & $\begin{array}{l}- \\
- \\
3 \\
3\end{array}$ \\
\hline
\end{tabular}

- N, Normal; BL, borderline; S, suppressed.

Men 11 (age range 18-68 yr, mean 49.6)

Women 14 (age range 19-70 yr, mean 48.9) 
subsequently required short courses of prednisone for reasons which will be discussed later in this paper.

In two patients it proved impossible either to withdraw or to reduce the maintenance dose of prednisone (10 $\mathrm{mg}$ daily) without causing an impending relapse (Table 3). A third patient, whose maintenance dose of prednisone was also $10 \mathrm{mg}$ daily experienced acute bronchoconstriction following the inhalation of BDA, and treatment with the latter had to be abandoned.

In none of the three patients taking more than $10 \mathrm{mg}$ prednisone daily was it possible to replace this completely by BDA (Tables 2 and 3). In one of them, however, BDA successfully controlled asthma, but withdrawal of prednisone was followed by the acute onset of rheumatoid arthritis. In this patient, and in one other, the addition of BDA enabled a reduction to be made in the maintenance dose of prednisone. In the third, reduction of prednisone dosage lead to a severe relapse of asthma, and also to the onset of acute polymyalgia rheumatica.

In the majority of patients whose maintenance dose of prednisone was more than $5 \mathrm{mg}$ daily adrenal function was suppressed before treatment with BDA was started (Table 2). In most of those whose adrenal function at the outset of the study was apparently normal or borderline, subsequent tetracosactrin challenge after withdrawal of prednisone showed that adrenal function had improved, signifying that some suppression had been present previously. Adrenal function eventually returned to normal in all patients in whom prednisone was successfully withdrawn. In one patient, reported elsewhere (Gregg, 1977), who had taken prednisone continuously for $15 \mathrm{yr}$ since childhood, adrenal function was severely suppressed, but returned to normal 3 months after prednisone had been withdrawn.

\section{Use of BDA in patients not under systemic cor- ticosteroid therapy}

After the study had been in progress for about 3 months, the use of BDA was studied in 14 patients who were not currently taking prednisone. Six patients had received short courses in the past, but in none of these had prednisone been given within the previous 3 months (Table 4).

All patients initially received BDA $400 \mu \mathrm{g}$ daily. The method of follow-up was similar to that already described, except that adrenal function was assessed only once, at the start of the trial. Several reports had been published by this time indicating that BDA in a dose of up to $1200 \mu \mathrm{g}$ daily did not cause adrenal suppression.

The initial tetracosactin challenge test was normal in all but one of the 14 patients. No clinical features of Addison's disease were present in the patient who was found to have adrenal insufficiency (basal plasma cortisol $100 \mathrm{nmol} / 1$; post-challenge serum cortisol $200 \mathrm{nmol} / \mathrm{l})$. This was the only patient whose asthma could not be controlled successfully by BDA alone, but her symptoms were eventually controlled with a combination of oral prednisone $7.5 \mathrm{mg}$ daily and BDA $600 \mu \mathrm{g}$ daily.

A short introductory course of prednisone was given to four patients, the object of this being to achieve maximal reversal of airflow obstruction so as

Table 3 Six 'corticosteroid-dependent' patients in whom complete substitution by BDA was not achieved

\begin{tabular}{|c|c|c|c|c|c|}
\hline \multirow[t]{2}{*}{ Sex } & \multirow[t]{2}{*}{ Age } & \multicolumn{2}{|c|}{$\begin{array}{c}\text { Previous corticosteroid } \\
\text { therapy }\end{array}$} & \multirow{2}{*}{$\begin{array}{l}\text { Tetracosactrin } \\
\text { challenge } \\
\text { Plasma cortisol } \\
\text { (nmol/l) }\end{array}$} & \multirow[t]{2}{*}{$\begin{array}{l}\text { Reasons for failure } \\
\text { and outcome }\end{array}$} \\
\hline & & $\begin{array}{c}\text { Dose } \\
\text { (mg daily) }\end{array}$ & $\begin{array}{c}\text { Duration } \\
\text { (yr) }\end{array}$ & & \\
\hline $\mathbf{F}$ & 43 & 10 & 9 & $30 \rightarrow 150$ & $\begin{array}{l}\text { Relapsed, no reduction } \\
\text { in maintenance dose }\end{array}$ \\
\hline$F$ & 31 & 10 & 3 & $150 \rightarrow 300$ & $\begin{array}{l}\text { Acute bronchoconstriction } \\
\text { caused by BDA }\end{array}$ \\
\hline $\mathbf{F}$ & 50 & 10 & 3 & $150 \rightarrow 150$ & $\begin{array}{l}\text { Relapsed, no reduction } \\
\text { in maintenance dose }\end{array}$ \\
\hline$F$ & 59 & 12.5 & 5 & $150 \rightarrow 500$ & $\begin{array}{l}\text { Maintenance dose } \\
\text { reduced to } 4 \mathrm{mg} \text { daily }\end{array}$ \\
\hline$F$ & 61 & 12.5 & 10 & $100 \rightarrow 150$ & $\begin{array}{l}\text { Relapsed, and onset of } \\
\text { polymyalgia rheumatica }\end{array}$ \\
\hline $\mathbf{M}$ & 68 & 12.5 & 4 & $300 \rightarrow 500$ & $\begin{array}{l}\text { Asthma controlled, but onset } \\
\text { of acute rheumatoid arthritis }\end{array}$ \\
\hline
\end{tabular}


to facilitate effective inhalation of BDA, and also to obtain an optimum value of PEF as a reference point for subsequent management.

\section{Side-efiects of BDA}

Few side-effects of BDA were encountered in the course of the study. Oropharyngeal candidiasis was identified clinically in only three patients, and this responded readily to treatment with amphotericin lozenges without interruption of BDA therapy. Transient hoarseness, which may have been due to candidiasis, was reported by several patients. A small haemoptysis occurred on two occasions in a patient with oropharyngeal candidiasis.

One patient complained of acute shortness of breath and wheeze following the inhalation of BDA. This was first noted about 4 weeks after she had started treatment with BDA, but she persisted with it for a further 2 weeks. A challenge test then confirmed that her PEF fell abruptly from 350 to $205 \mathrm{l} / \mathrm{min}$ within $5 \mathrm{~min}$ of inhaling BDA. A few days later she was given an aerosol containing only the propellant, and after inhalation her PEF fell from 240 to $155 \mathrm{l} / \mathrm{min}$.

\section{Problems arising in the substitution of BDA for systemic corticosteroid therapy}

Although adrenal suppression was present in the majority of patients who had previously been taking prednisone, no problems were encountered which could be directly attributed to this. One patient developed generalized joint and muscle pains, with a high erythrocyte sedimentation rate (ESR), which may have been an example of corticosteroid pseudorheumatism, a condition which has been reported in corticosteroid-dependent asthmatic patients in whom corticosteroids were being replaced by sodium cromoglycate (Hargreave et al., 1969). In several patients the withdrawal of prednisone unmasked conditions which previously had been suppressed by it, notably eczema, allergic rhinitis and nasal polypi. One patient had an acute onset of rheumatoid arthritis, from which he had never previously suffered, and another developed polymyalgia rheumatica.

\section{Problems arising in the long-term use of BDA}

Even in the course of the comparatively short followup, most patients who were taking BDA as their sole form of maintenance corticosteroid therapy required at least one short course of prednisone. All had been given a reserve supply of prednisone, and were told to take this on their own initiative if their asthma became worse or if they developed a 'chest cold'. Some patients, however, were so delighted to have stopped taking prednisone that they were reluctant to resume this treatment even for only a few days. One such patient, whose case-history has been reported elsewhere (Hodson et al., 1974), had a respiratory infection, during which she became unable to inhale BDA effectively. She neither sought medical advice nor took her reserve supply of prednisone, and was admitted to hospital in status asthmaticus.

Because patients were closely followed up, and also because great care had been taken at the start of the study to explain to every patient the purpose and proper use of BDA, no other serious problems were encountered.

\section{Discussion}

The findings of this study suggested that BDA was a major advance in the treatment of asthma. Subsequent experience has not only provided ample confirmation of this view, but has also clarified a number of problems which were not fully resolved by any of the early trials of BDA.

One of the aims of this study was to determine whether it was essential to monitor adrenal function in all patients in whom systemic corticosteroid therapy was to be replaced by BDA. Because it had seldom

Table 4 Patients not currently taking maintenance corticosteroid therapy

$\begin{array}{lcccccccc} & \begin{array}{c}\text { Number of } \\ \text { patients }\end{array} & \begin{array}{c}\text { Adrenal } \\ \text { function }\end{array} & \begin{array}{c}\text { Given } \\ \text { introductory } \\ \text { course of } \\ \text { prednisone }\end{array} & \text { Success } & \text { Failure } \\ \begin{array}{l}\text { Never previously given } \\ \text { corticosteroids }\end{array} & 8 & 7 & - & 1 & 3 & 7 & 1 \\ \begin{array}{l}\text { Previous short courses } \\ \text { of corticosteroids }\end{array} & 6 & 6 & - & - & 1 & 6 & 0\end{array}$

* N, Normal; BL, borderline; S, suppressed. 
been possible before the advent of BDA to withdraw corticosteroids from patients on long-term treatment, there was little information about the length of time required for adrenal function to return to normal or about the dangers which might arise before it had done so.

The findings of this and many other surveys have shown that severe adrenal suppression is likely to be present in those patients who have taken a high maintenance dose of prednisone for many years. Yet, in almost every patient adrenal function returned to normal within a few weeks after its withdrawal. Therefore, it would seem that tetracosactrin challenge tests are generally unnecessary, provided that substitution of BDA for prednisone is carried out cautiously.

The findings of this study suggest that in most patients taking a maintenance dose of prednisone of not more than $10 \mathrm{mg}$ daily, the latter can be replaced completely by BDA in the usual dose of $400 \mu$ g daily. Similar findings have been reported by other workers. Morrow Brown et al. (1972) found that $80 \%$ of 30 patients taking up to $10 \mathrm{mg}$ prednisone daily could be transferred to BDA, whereas substitution was successful in only one of four patients taking a higher dose. Lal et al. (1972) concluded that BDA $300 \mu \mathrm{g}$ daily was equivalent in effect to prednisone $7.5 \mathrm{mg}$ daily. Clark (1972) considered that BDA $400 \mu \mathrm{g}$ was approximately equivalent to prednisone $10 \mathrm{mg}$ daily. There is less information about the possibility of replacing higher maintenance doses of prednisone by BDA given in a higher dose. Costello \& Clark (1974) reported that patients who had responded poorly to BDA $400 \mu \mathrm{g}$ daily showed a significant improvement when the dose was increased to $1000 \mu \mathrm{g}$ daily.

Paradoxically, the very quality which has made BDA such a valuable addition to the therapy of asthma - that is, its topical action-also gives rise to its principal limitation, for in order to reach its site of action the aerosol has to be inhaled. Although there is little evidence on this point, it seems probable that the depth of inhalation is a factor of great importance, and that the efficacy of BDA depends on its reaching the smaller airways. Therefore, it seems prudent to advise all patients to take an inhalation of a bronchodilator aerosol a few minutes before they inhale BDA. For similar reasons, in those patients who are not currently taking maintenance corticosteroids a short introductory course of prednisone is advisable at the start of BDA therapy.

Patients in whom BDA is the sole form of long-term corticosteroid therapy must be given a reserve supply of prednisone, and should be instructed to take this on their own initiative whenever they have a relapse of asthma or a lower respiratory infection. The danger of being deprived of corticosteroid therapy at times when BDA cannot be inhaled effectively was clearly seen in one patient who had a severe episode of status asthmaticus. In a recent review of childhood mortality from asthma in Australia, Mellis \& Phelan (1977) reported three deaths in children under very similar circumstances.

Undoubtedly, BDA is often prescribed without the patient being given clear instructions about its purpose. It is not uncommon to find that a patient believes BDA to be another form of bronchodilator aerosol. This misunderstanding has probably arisen, in part, from the unfortunate resemblance between the pressurized canisters containing BDA and those containing bronchodilators. Some patients are unable to synchronize the action of the canister with inspiration. It seems probable that the high incidence of oropharyngeal candidiasis reported by some workers is due to a high concentration of BDA impinging on the pharynx instead of being swept into the lower respiratory tract.

Recently, BDA has been prepared in the form of a fine powder which is inhaled by means of a device similar to the Spinhaler used for sodium cromoglycate. Preliminary experience suggests that patients find BDA much easier to inhale in this form than as an aerosol delivered from a pressurized canister (unpublished data).

Before the advent of BDA, steroid therapy had to be given systemically and was widely regarded as a 'last resort' treatment for asthma. Although the incidence of dangerous side-effects is far less than is generally supposed, even the least serious side-effect of facial disfigurement is distressing to patients. The fear of inducing side-effects made some clinicians very reluctant to use systemic corticosteroids, and consequently many patients with moderately severe asthma were deprived of the only form of treatment which could have been effective in relieving their airflow obstruction. One of the principal benefits of BDA is that clinicians may no longer be so hesitant to use systemic corticosteroids, knowing that they should be able to withdraw them under cover of BDA, once the immediate objective of restoring ventilatory function has been achieved. Therefore, the introduction of BDA should result in a greater readiness to prescribe steroid therapy on a preemptive' basis in patients who may not be dangerously ill, yet have a considerable degree of refractory airflow obstruction which, if left unrelieved over a long period, may become irreversible.

I thank Dr Richard Harris, formerly of the Chemical Pathology Department at Queen Mary's Hospital, Roehampton, for carrying out the tetracosactrin challenge tests; and Dr J.B.C. Evelegh and Dr A.G. Huff, Roehampton, for permission to study their patients. BDA was kindly supplied by Dr David Harris of Allen \& Hanburys Research Limited. 


\section{References}

BROWN, H. MORROW, STOREY, G. \& GEORGE, W.H.S. (1972). Beclomethasone dipropionate: A new steroid aerosol for the treatment of allergic asthma. Br. med.J., $1,585-590$.

CLARK, T.J.H. (1972). Effect of beclomethasone dipropionate delivered by aerosol in patients with asthma. Lancet, 1, 1361-1364.

COSTELLO, J.F. \& CLARK, T.J.H. (1974). Response of patients receiving high dose beclomethasone dipropionate. Thorax, 29, 571-573.

GREIG, W.R., BROWNING, C.K., BOYLE, J.A. \& MAXWELL, J.D. (1966). Effect of the synthetic polypeptide B1-24 (Synacthen) on adrenocortical function. J. Endocrin., 34, 411-412.

GREGG, I. (1970). Clinical experience with disodium cromoglycate and assessment of its steroid-sparing action. In Disodium Cromoglycate in Allergic Airways
Disease, 177-187, ed. Pepys, J. \& Frankland, A.W. London: Butterworths.

GREGG, I. (1977). The difficult asthamatic. Drugs, 13, $35-45$.

HARGREAVE, F.E., McCARTHY, D.S. \& PEPYS, J. (1969). Steroid pseudorheumatism in asthma. Br. med. J., 1, 443-444.

HODSON, M.E., BATTEN, J.C., CLARKE, S.W. \& GREGG, I. (1974). Beclomethasone dipropionate aerosol in asthma. Am. Rev. Resp. Dis., 110, 403-408.

LAL. S., HARRIS, D.M., BHALLA, K.K., SINGHAL, S.N. \& BUTLER, A.G. (1972). Comparison of beclomethasone dipropionate aerosol and prednisolone in reversible airways obstruction. Br. med.J., 3, 314-317.

MELLIS, C.M. \& PHELAN, P.D. (1977). Asthma deaths in children - a continuing problem. Thorax, 32, 29-34. 